\title{
Quantitative Analysis of Human Factors in Mass Transportation Accidents
}

\author{
Yoo Kyung Won ${ }^{1}$, Dong Jin Kim ${ }^{2}$ \\ ${ }^{1,2}$ Department of International Trade, Pusan National University, Busan, Korea \\ ${ }^{1}$ charmhanai@gmail.com, ${ }^{2}$ ssskdj@hanmail.net
}

\begin{abstract}
Accidents which are mainly due to carelessness of safety have been increasing these days and the types and causes of accidents have also diversified more and more. Also accidents coming from human error account for most accidents and moreover, damages and losses occurred are often severe enough to threaten the human life. In this context, mitigation measures are necessary and to establish reasonable mitigation measures risk analysis and cause analyzes should be performed first. Therefore this study deals with the railway accidents and maritime accidents which lead to huge economic damage and damage of human life. We propose risk matrix using frequency and consequence to evaluate the risk by accident type and specify the risk characteristics of each accident type We also investigate the main cause for each accident type by applying a cause-specific matrix. As our main focus, among various causes, we analyze the causes in terms of human error and this will help decision makers to establish effective and systematic mitigation measures.
\end{abstract}

Keywords: transportation accidents, quantitative risk analysis, risk matrix, frequency-consequence, human error

\section{Introduction}

In recent years, most of transportation accidents occurring in Korea are becoming more diverse in types and causes. Especially, accidents due to the human error happen more frequently and most of transportation accidents are caused by human errors. Accidents related to the transportation among various types of accidents can cause severe human loss and economic loss, and have a negative impact on not only national security but also national competitiveness. Therefore, it is necessary to establish mitigation measures to reduce accidents caused by transportation. And risk analysis must be performed first to quantitatively find out negative effect of each cause of the accident due to human errors. Based on the result of the analysis, we can suggest efficient mitigation measures to reduce the accident. Literature studies on railway accidents and maritime accidents investigates the risk of accidents using only frequency of accidents by type of accidents, and there are not enough studies to analyze the causes of accidents in detail. In the study, to quantify the negative effects of accidents on railway accidents and maritime accidents, we calculate the risk of cause on type of accident through the risk assessment and the risk matrix. In other words, in transportation accidents, which are mostly caused by human errors, we try to figure out most risky cause of accidents by caculating risk level quantitatively. The result will be helpful for the decision makers to establish appropriate accident mitigation measures in the future.

\section{Cause-specific Risk Analysis by accident type in Railway Accident}

In the risk analysis, the risk of an accident is represented by a combination of two main factors, the probability of occurrence (frequency) and the number of fatality(consequence), and is generally calculated as a function of the frequency and consequence in the formula as below.

$$
\mathrm{R}=\mathrm{P} \times \mathrm{C}
$$

where $\mathrm{R}$ is the risk of an accident, $\mathrm{P}$ is the frequency of the accident (probability), and $\mathrm{C}$ is the consequence of an accident(loss of life, environmental damage, economic damage, etc.). In this study, the frequency of accidents is used as the ratio of accident type to the total number of accidents. The consequence of the accident includes human loss and economic loss. The number of fatality is converted to corresponding weight using the MAIS level (death: 1 , serious injury: 0.7625 , minor injury: 0.1875 ) in order to include potential fatality. We used the frequency of the accident, casualties and economic damages from 2007 to 2016 on the three types of accidents which are collision, derailments and level crossing from the Rail Safey Information System(RSIS, hereinafter). Based on the causes of accidents classified by RSIS, risk level for each cause by type of accident is calculated by formula (1) and risk graphs are presented. Train accidents(collision, derailments) and level crossing accidents were analyzed separately because their causes of accidents are different from each other.

\section{Cause-specific risk analysis for collision and derailments}

$<$ Table 1.> shows the classification for cause of train accidents classified by RSIS. According to the $<$ Table 1.>, eight sub causes(cause 1 8) are classified into human error as top cause and the remaining five sub causes(cause 9 13) belong to mechanical defects as top cause. 
$<$ Table 1. Classification for cause of railway accident>

\begin{tabular}{|c|c|c|}
\hline Top Cause & $\begin{array}{c}\text { Cause } \\
\text { No. }\end{array}$ & Sub cause \\
\hline \multirow{7}{*}{$\begin{array}{c}\text { Human } \\
\text { Error }\end{array}$} & 1 & Signal violation by driver \\
\cline { 2 - 3 } & 2 & Over speed by driver \\
\cline { 2 - 3 } & 3 & $\begin{array}{c}\text { Signal handling fault } \\
\text { by controller }\end{array}$ \\
\cline { 2 - 3 } & 5 & $\begin{array}{c}\text { Wrong driving order } \\
\text { by controller }\end{array}$ \\
\cline { 2 - 3 } & 6 & Carelessness by maintainer \\
\cline { 2 - 3 } & 7 & $\begin{array}{c}\text { Inadequate maintenance } \\
\text { by maintainer }\end{array}$ \\
\cline { 2 - 3 } & 8 & Etc by human factors \\
\hline \multirow{4}{*}{$\begin{array}{c}\text { Mechanical } \\
\text { Defect }\end{array}$} & 9 & Driving gear device failure \\
\cline { 2 - 3 } & 10 & $\begin{array}{c}\text { Occlusion signal device } \\
\text { failure }\end{array}$ \\
\cline { 2 - 3 } & 11 & Track and structure \\
\cline { 2 - 3 } & 13 & Etc. by mechanical factors \\
\cline { 2 - 3 } & 13 & External factors \\
\hline
\end{tabular}

First, $<$ Fig 1. $>$ shows the risk level(R1) of each cause with human loss as consequence and $<$ Fig 2 . $>$ represents the risk level(R2) of each cause with economic loss as consequence in case of collision. The horizontal axis of the graph represents the risk and the vertical axis represents the cause of each accident. As shown in $<$ Fig 1.>, risk level of cause 8 (Etc. by human factors) is 10.209 ranked the most risky cause, and cause 1 (Signal violation by driver) ranked second, cause 2(Over speed by driver) ranked third. It means that cause due to human error results in most negative human loss. In the risk analysis with economic loss as shown in $<$ Fig 2 . $>$, the cause 1 is the highest with $11,414,688$, followed by the cause 8 and the cause 2 . It also shows that sub cause under'human error' leads to most serious economic loss. In the case of collision, three major sub causes of accidents were common in both R1 and R2, and those belong to 'human error' as top cause. It implies that human error is more important issue to set up mitigation measures. On the other hands, the most risky causes are different from R1 and R2. Cause 8 is the most risky in $\mathrm{R} 1$, while cause 1 is the most risky in $\mathrm{R} 2$, so it shows that we need to focus on different human error type for different consequence of accidents.

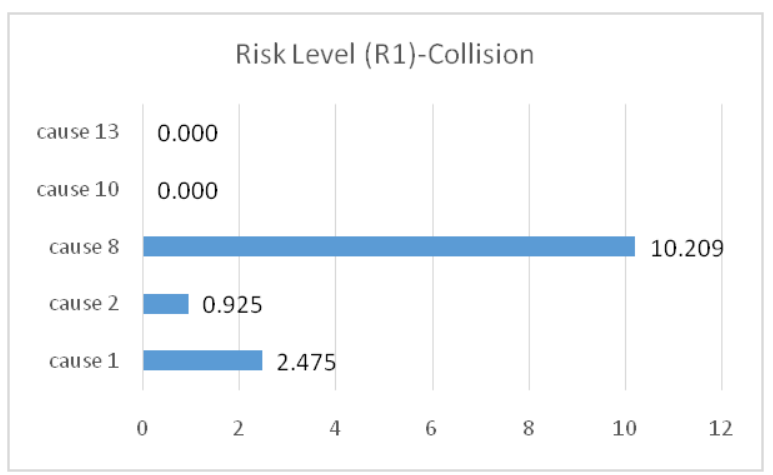

$<$ Fig 1. Risk Level(R1) - Collision $>$

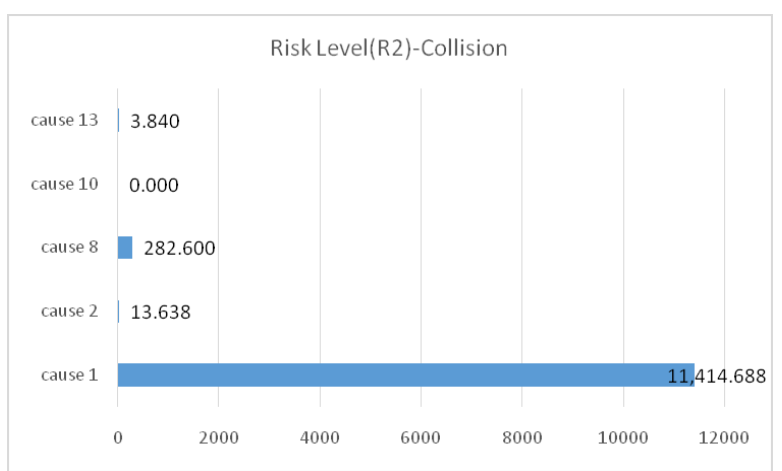

$<$ Fig 2. Risk Level(R2) - Collision>

Second, $<$ Fig 3. $>$ and $<$ Fig 4. $>$ show the risk level with human $\operatorname{loss}(\mathrm{R} 1)$ and risk level with economic loss(R2) for the derailments. According to the graphs, causes for risk level with human loss are simple and a few but causes for risk level with economic loss are various and a lot. In case of derailment, unlike collision, causes for three risky rank are different in R1 and R2. In the risk analysis(R1) by human loss, cause 2(Over speed by driver) is 0.253 , the most risky cause and cause 8 is next. And in the risk analysis(R2) caculating by economic loss, cause 9(Driving gear device failure) records 377.271 as the most risky cause and cause 12(Etc. by mechanical factors) and cause 2(Over speed by driver) follow. The result shows that the cause 2 is a common cause for risk analysis by human loss and economic loss and it is classfied into human error as top cause from $<$ Table 1. $>$. In addition, cause 8 and cause 2 under the human error are main cause for human loss but cause 9 and cause 12 under the mechanical defects are main cause for economic loss. It is totally different result from the collision. According to the result, the most risky cause is different in terms of risk level for different types of consequences. Therefore different mitigation measures should be prepared by types of consequences such as human loss and economic loss.

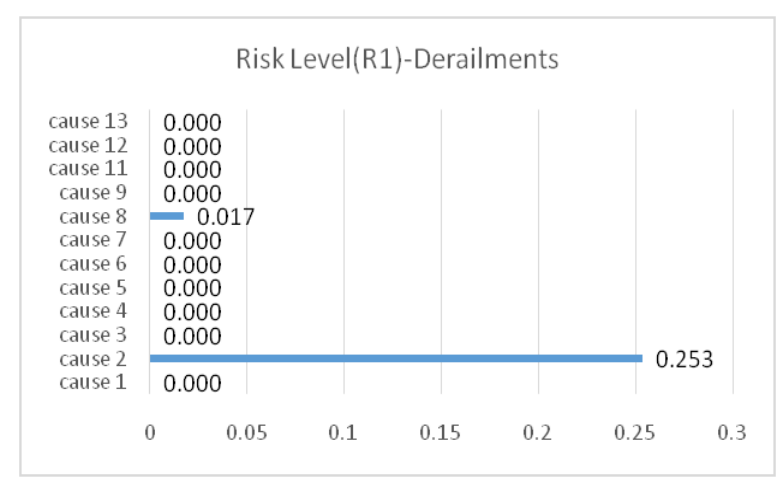

$<$ Fig 3. Risk Level(R1) of Derailments $>$ 


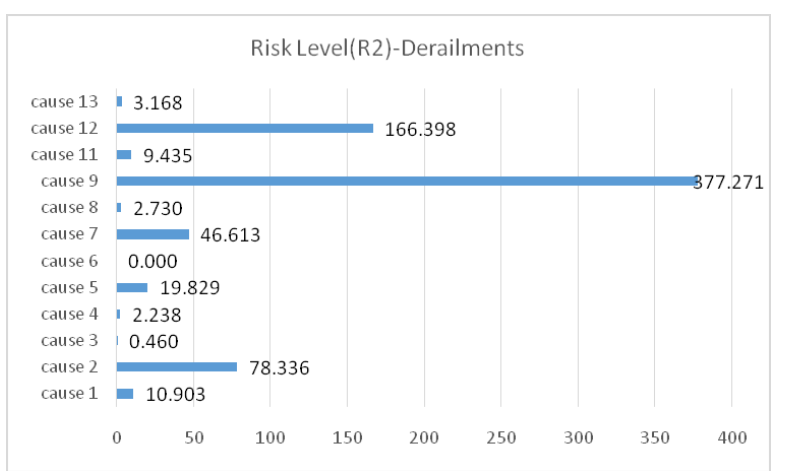

$<$ Fig 4. Risk Level(R2) of Derailments $>$

\section{Cause-specific risk analysis for level crossing}

$<$ Table 2.> below shows the classification for cause of level crossing by RSIS. According to the <Table 2.>, eight sub causes(cause $1 \sim 8$ ) are classified into human error and the other(cause 9) belongs to mechanical defect. As in the cause of collision and derailments, most of the causes of level crossing are human errors.

$<$ Table 2. Classification for cause of level crossing $>$

\begin{tabular}{|c|c|c|}
\hline Top Cause & $\begin{array}{c}\text { Cause } \\
\text { No. }\end{array}$ & Sub cause \\
\hline \multirow{4}{*}{$\begin{array}{c}\text { Human } \\
\text { Error }\end{array}$} & 1 & Safety device operation fault \\
\cline { 2 - 3 } & 2 & Vehicle access control \\
\cline { 2 - 3 } & 3 & Train protection failure \\
\cline { 2 - 3 } & 5 & $\begin{array}{c}\text { Jay walk with violation of } \\
\text { stop sign }\end{array}$ \\
\cline { 2 - 3 } & 6 & Breaker breaking / detour \\
\cline { 2 - 3 } & 7 & Crossing board \\
\cline { 2 - 3 } & 8 & Delay in crossing \\
\hline $\begin{array}{c}\text { Mechanical } \\
\text { Defect }\end{array}$ & 9 & Safety device \\
\hline
\end{tabular}

$<$ Fig.5. $>$ and $<$ Fig 6. $>$ show the risk level(R1) by human loss and the risk level(R2) by economic loss in case of level crossing. In case of level crossing, main causes for R1 and R2 are same(cause 4, cause 5, cause 8) and risk ranking is also same for both $\mathrm{R} 1$ and $\mathrm{R} 2$. The cause 4(Jay walk with violation of stop sign) is 12.476 in $\mathrm{R} 1$ and 175.532 in R2 as the most risky cause. And cause 5(Breaker breaking/ detour) and cause 8(Delay in crossing) follow. All three main causes of level crossing are classified into human error, which shows that risk of level crossing with human loss and economic loss occurs by human errors. Therefore to reduce the risk of level crossing, we need to prepare mitigation measures by focusing on the human error.

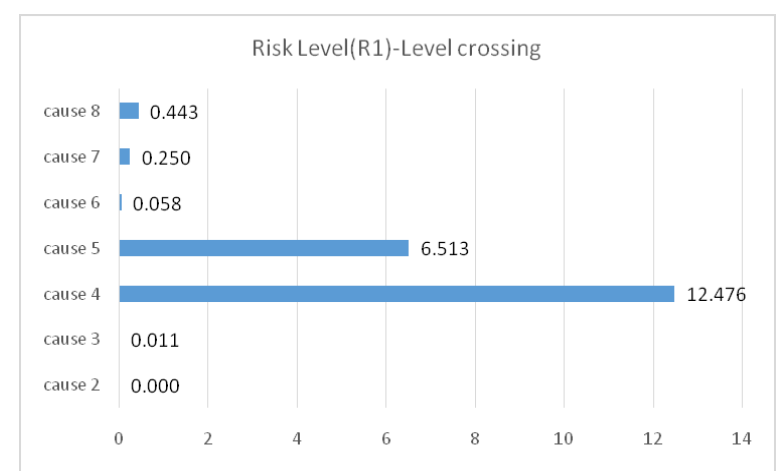

$<$ Fig 5. Risk Level(R1) of Level crossing $>$

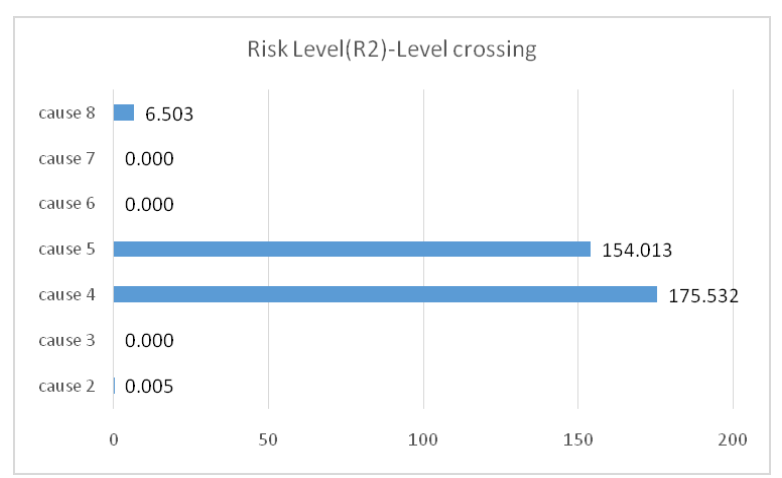

$<$ Fig 6. Risk Level(R2) of Level crossing $>$

\section{Cause-specific Risk Analysis by accident type in Maritime Accident}

In the case of maritime accidents, the risk analysis was carried out for fishing vessels and merchant vessels which include passenger ship, cargo ship, oil tanker and tug boat. And risk level of each cause is analyzed by different types of accidents. In the risk analysis, for the frequency is converted to the probability by using the same method as the railway accident. For fatalities, the injured and missing people were converted by conversion coefficient(missing: 0.996, injured: 0.043) from Kim et al(2013). In this study, we used past 5 years(2014 2018) accident data from the Korea Maritime Safety Tribunal(KMST) and classified accident type into 9 types (collision, touching, stranding, capsizing, fire-explosion, sinking, engine failure, death-injury, and etc.). The main causes of accidents by type of accident were derived using the risk matrix according to the vessel type and the results are shown in the $<$ Fig 7 . $>$ and $<$ Fig 8 . $>$ below. $<$ Table 3. $>$ describes the classification for cause of maritime accidents by KMST. The three top causes have several sub causes, so there are totally $22 \mathrm{sub}$ causes. In the <Table 3.>, operation faults are caused by human errors, fault in handle \& defect are due to the mechanical faults and others are mixed with both. 
$<$ Table 3.Classification for cause of maritime accident $>$

\begin{tabular}{|c|c|c|}
\hline Top cause & $\begin{array}{l}\text { Cause } \\
\text { No. }\end{array}$ & Sub cause \\
\hline \multirow{13}{*}{$\begin{array}{l}\text { Operational } \\
\text { Fault }\end{array}$} & 1 & $\begin{array}{l}\text { Unsuitable preparation } \\
\text { for sailing }\end{array}$ \\
\hline & 2 & Insufficient water survey \\
\hline & 3 & Poor selection \\
\hline & 4 & $\begin{array}{l}\text { Inattention of } \\
\text { confirmation of position }\end{array}$ \\
\hline & 5 & Improper shipbuilding \\
\hline & 6 & Poor watching \\
\hline & 7 & $\begin{array}{l}\text { Poor action on bad } \\
\text { weather }\end{array}$ \\
\hline & 8 & Unsuitable anchoring \\
\hline & 9 & $\begin{array}{l}\text { Not comply with the } \\
\text { sailing rules }\end{array}$ \\
\hline & 10 & $\begin{array}{l}\text { Inattention on a director } \\
\text { of service }\end{array}$ \\
\hline & 11 & Failure in duty \\
\hline & 12 & Others \\
\hline & 13 & $\begin{array}{l}\text { Incomplete work safety } \\
\text { rules }\end{array}$ \\
\hline \multirow{3}{*}{$\begin{array}{c}\text { Fault in } \\
\text { handle \& } \\
\text { defect }\end{array}$} & 14 & Fault in handle engine \\
\hline & 15 & $\begin{array}{l}\text { Fault in electricity and } \\
\text { fire equipment }\end{array}$ \\
\hline & 16 & Fault in hull and engine \\
\hline \multirow{6}{*}{ Others } & 17 & Poor cargo loading \\
\hline & 18 & $\begin{array}{l}\text { Inproper ship operating } \\
\text { management }\end{array}$ \\
\hline & 19 & $\begin{array}{l}\text { Poor work and } \\
\text { environmental condition }\end{array}$ \\
\hline & 20 & $\begin{array}{l}\text { Inadequate navigational } \\
\text { aids }\end{array}$ \\
\hline & 21 & Irresistible force \\
\hline & 22 & Others \\
\hline
\end{tabular}

Using the frequency and consequence of the accident, a risk matrix was constructed to identify the risks by each cause of the accident more in detail. This paper presents the results of a collision as a representative case, which is the most dangerous accident type for both fishing vessels and merchant vessels. $<$ Fig. $7>$ shows the risk matrix for each cause of merchant vessels in collision, the $\mathrm{X}$-axis shows the frequency of an $\operatorname{accident}(\mathrm{P})$ and the $\mathrm{Y}$-axis shows the consequence of an accident(C). The red horizontal line represents the average of the $\mathrm{C}$, and the red vertical line represents the average of the $\mathrm{P}$ of accident by cause. Based on these two lines, causespecific risk matrix is divided into four regions. And the causes in the first quadrant where both $\mathrm{P}$ and $\mathrm{C}$ values are higher than the average value corresponds to the highest risk factor with the highest risk. According to $<$ Fig 7. - 8.>, in case of merchant vessel, cause 6 (Poor watching) and cause 9(Not comply with the sailing rules) appear as the highest risky causes. In case of fishing vessel, cause 6 corresponds to the highest risky cause. These two causes correspond to human errors, Especially, cause 6 is common cause of collision in both type of vessels.

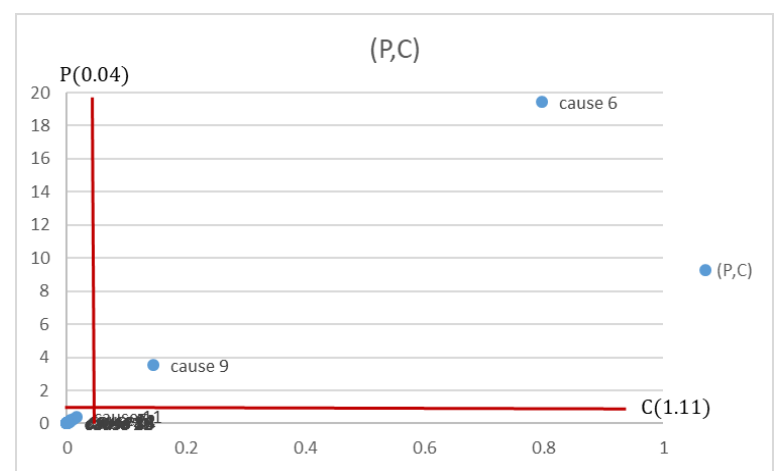

$<$ Fig 7. Risk matrix of collision in merchant vessel $>$

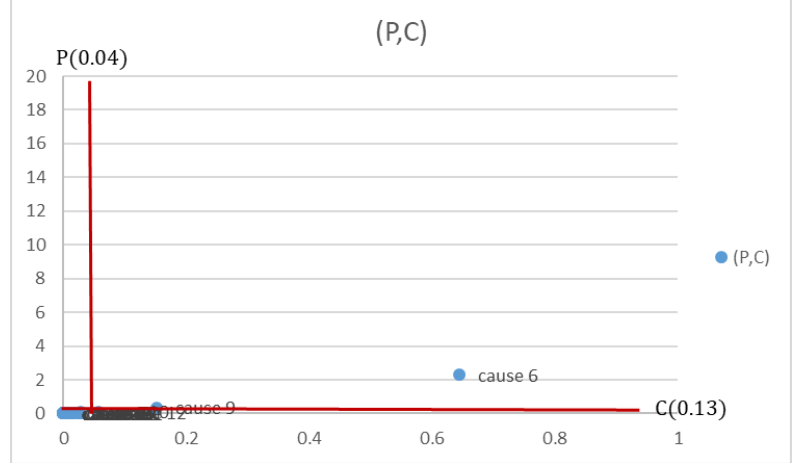

$<$ Fig 8 . Risk matrix of collision in fishing vessel $>$

\section{Conclusion}

In this study, the risk analysis of railway accident of Korea is conducted by risk assessment where human factors and signal violation are shown to be the most risky cause in risk with human loss and risk with economic loss respectively in collision. And in the derailments, main causes are over speed in human loss and driving equipment failure in economic loss. The risk analysis of maritime accident of Korea is conducted by risk matrix for two different vessels. In the result of the analysis, in collision, the main cause for high risk is poor watching in both vessels. Based on the proposed risk analysis, we can figure out the main cause for each accident types and most of accidents occur due to the human errors. Therefore it suggests that we need to focus on the human factors to establish practical risk mitigation measures to lower the overall risk. In future study, to gain more detailed insight into the result of the risk analysis, both human loss and economic loss should be conbined into consequence in order to calculate the total risk level.

\section{References}

[1] Pillay, A., C. G. Loughran, J. Wang, A. Wall, T. Ruxton: Formal safety assessment of fishing vessels: Risk and maintenance modelling, Journal of marine engineering and technology, 2004(4):29-42, 2004.

[2] RSSB, Rail-specific Human Reliability Assessment Technique for Driving Tasks, Research Project T270, Final Report, London: Rail Safety \& Standards Board, 2005.

[3] Kim and Kwak, "Risk Analysis of Container Ship Accidents and Risk Mitigation Measures", Journal of Korean Society and Marine Environment \& Safety, 22(3): 259-267. 